\title{
Medical physiology as a walk of life -past, current, and future prospective: An insight
}

\author{
Aparna Mulgund ${ }^{1}$, Nagaraja Puranik ${ }^{2}$
}

1. Phase I MBBS student, Karnataka Institute of Medical Sciences, Hubballi, Karnataka, India.

2. Professor, Department of Physiology, Karnataka Institute of Medical Sciences, Hubballi, Karnataka, India.

\begin{abstract}
I n exploring the epitome of Physiology, we come across a multitude of disciplines. The history of human Physiology can be traced back to 435 BC. Now, Physiology has become an integral part of our life. Physiology and Medicine are like two faces of the same coin. While swimming through the ocean of Physiology, we discover many natal systems. Physiology forms the ground on which the study of Medicine works like our laptop. Forming substratum in the arch of medical and surgical knowledge, Physiology is gaining vanity. The relevance of Physiological ideas is just like the cherry on the cake. This review is a general topic of interest and discusses the history of Physiology and the importance of Physiology beyond academics in the epoch of translational research.
\end{abstract}

KEYWORDS: Physiology, Medicine, Physiological ideas, Neurophysiology, Translational research.

\section{INTRODUCTION}

"In Physiology, no discovery is useless, no curiosity misplaced or too ambitious, and we may be certain that every advance achieved in the quest of pure knowledge will sooner or later play its part in the service of man" - Ernest Henry Starling.

\section{What is Physiology for you?}

For an infant, it's blithe, for a school going youngster, it's worthwhile checking in a dictionary. For a biology student, it's a marks acquirement part, for a medical student, it's something exciting but confused about how to get the answer and which book to be referred to. For a postgraduate student, it is slowly becoming a part of his/her life and to read the available book. For a Professor in a medical college, it's God. For a nosy scientist, it's anonymity. But, for an instigator, it's a joy to express his/her thoughts with astonishing and precious readers like you all. I hope you will enjoy the quintessence of Physiology.

Human Physiology explores the physiological function and explains the abnormal function that occurs in many disorders/diseases. It accentuates the hypothesis which explains many physiological phenomena and combines many therapies to conquer pathological conditions [1]. Physiology in Greek, "Physis" means nature and "logia" means study, which deals with the study of normal functions within the living organisms. As a sub-discipline of biology, it deals with the mechanisms, which facilitate the interaction between cells and organ systems. Early theories, molecular laboratory research findings have formed our ideas about how these necessary machineries of the body communicate to keep us alive [2]. A modern medical practice requires a

Correspondence: Dr. Nagaraja Puranik. Professor; Department of Physiology, Karnataka Institute of Medical Sciences, Hubballi, Karnataka, India. E-mail: aparnaamulgund@gmail.com 
sound knowledge of Physiology. This knowledge aids in proper diagnosis and effective treatment [3]. Physiology can be categorized into medical Physiology, Animal Physiology, Plant Physiology, Cell Physiology, Comparative Physiology, etc.

\section{Physiology: A multitude of disciplines within human BIOLOGY AND BEYOND}

Physiology integrates the working of the internal environment of an organism, and it's interaction with the external environment [4]. Researchers in Physiology can spotlight on any point starting from minute organelles in Cell Physiology up to the broader field like Ecophysiology, which deals with the adaptation of organisms to their environment. The most relevant section of research in Physiology is Applied Physiology. It explores the natal systems at different levels, i.e., the cellular level, tissue level, organ's level, and system levels [5].

\section{Pithy History of Physiology}

\section{Physiology and Medicine at Early days}

During the early days, Psychology was also associated with Biology, Human Physiology, and Medicine. This association is foreseeable as long as the mind is attached to our body. The body can't be detached from the mind as it works as per the command received by its master, which is the center for a perpetual soul.

The ancient Greek, Asclepius, was considered as 'the first physician.' In those days, he gained god-like eminence. He established a partially supernatural society or association of physicians. Greek philosopher Socrates, during his last few days to die of an overdose of hemlock, told his student Crito to sacrifice a cock to Asclepius as gratefulness for a painless death [6]. The term 'Physiology' was introduced by a French physician, Jean Fernel (1497-1558) to explain the study of the body's function [7].

It is the Alcmaeon of Croton (b 435BC), who is considered as one of the most renowned natural philosophers and medical theorists of ancient times. He was considered as 'scholar' and was known for his anatomical studies. He was the first person to discover the optic nerve and to identify the Eustachian tube. He described the 'theory of the mind,' which explained that the brain was the seat of perception and collected the information from all the sense organs. He hypothesized that; it was 'Pneuma' (breath or spirit) that ran through the body, like neural signals. He proposed theories on the internal causes of sickness. According to him, health is a condition of balance between opposing delight like hot and cold or bitter and sweet. The parity between cordiality results in health, but the realm among them results in disease [8].

The early medical tradition started in India, Babylon, Egypt, and China. Medical diagnosis, prognosis, and complex medical ethics were introduced by the Greeks [9]. Even today, before entering into the profession, doctors swear upon the 'Hippocratic Oath' (written in Greece in 5th century BC), which emulate the medical ethics and is an inspiring oath for the health professionals [10].

Since the primeval days, plants were used for medical problems, known as herbalism. Plants were used as healing mediators along with flora, clay, and soil. Tribal culture 'Shamans and apothecaries,' which was specific to a group of people, could fulfill the role of healer. Later on, as medical knowledge developed, this tradition was passed between successive generations [11].

Medical tradition thrived in Ancient Egyptians. According to Herodotus, Greek historian Egyptians were considered as "the healthiest people, next to the Libyans," due to the unique public health care system they acquired[12]. He explained that 'medical profession was normal practice for everyone during those days, and each one could be considered as a doctor.' It sounds that Egyptian medicine deals with mystical ideas. However, it ultimately has a practical utility in the field of anatomy, diagnosis, and public health [13].

The 'first Indian texts dealing with medicine' was the Atharvaveda. It is one of the sanctified texts of Hinduism starting from the early Iron Age [14]. This transcript explains prescriptions of herbs for various illnesses, which later created a basis for the vast part of Ayurveda. Ayurveda, a system of alternative Medicine, a native of India. In Sanskrit, Ayuh - life and Vedah- knowledge, i.e., Vital power of knowledge. It is believed that Ayurveda is the metamorphosis of medical knowledge from Gods to sages then to physicians. Ayurveda deals with herbal preparations, used to cure illness as therapy, dating from $600 \mathrm{BCE}$ onwards. Ayurveda has two most famous texts exemplified by Charaka and Sushruta [15].

Charaka, a compiler of an ancient medical system, describes in his compilation, "The Charaka Samhita,' 'fitness and malady are not predestined, and life may be drawn out by human efforts.' Another ancient surgeon, Sushruta, in his compilation, 'The Susrutasamhita,'describes that the idea of treatment is to cure diseases, taking care of the health of the individual and up course to increase life expectancy [16]. The spectacular facet of the Susrutasamhita is that it explains the different practices of surgery, including Rhinoplasty Cataract surgery and other surgical procedures. Sushruta is privileged as "the father of Indian Surgery."

China is known for its traditional Medicine. It was mainly on experimental annotations of disease by Taoist physicians. Chinese had a strong belief that every person experiences and expresses the cause for his/her illness in different ways. The contributing factor correlates as the expression of the standard command of the creation [17].

In 1628 , physiological acquaintance with 
Medicine took a jump forward due to a publication of William Harvey's book. His tome, "An Anatomical Dissertation upon the Movement of the Heart and Blood in Animals," was a boom for the change. Harvey was the first person to illustrate the systemic circulation. He described the journey of blood through the brain and body, which is impelled by the central pump, the heart [18]. In the 18th century, a theory known as 'cell theory of Matthias Schleiden and Theodor Schwann' was put forwarded. This theory elucidated that 'Cells' are the building blocks of the body [19].

\section{Physiology: As the natal system}

Human Physiology deals with the study of different biological systems [20]. They are as follows-

- Cardiovascular system: It is the study of heart and blood vessels. The cardiovascular system deals with the circulation of blood in the vessels, which transports nutrition, gases, hormones, etc.

- Digestive system: This system deals with the digestion and absorption of the food and how they are regulated in the body.

- Respiratory system: This system deals with the exchange of gases.

- Endocrine system: It is a system of a chemical messenger. It explains the different feedback mechanisms for the release of hormones by ductless glands into the circulatory system and their physiological and pharmacological actions.

- Immune system: It is the system concerned with the body's defense mechanism.

- Musculoskeletal system: System of skeleton, muscles, tendons, ligaments, and cartilage. They provide support, stability, and aid in mobility.

- Nervous system - It is a highly intricate system of our body. It coordinates the sensory information with motor actions by transmitting signals to and from the different parts of the body.

- Renal system - This system reabsorbs or removes water and electrolytes from the blood and helps in removing the waste materials from the body.

- Reproductive system - It is a system of gonads and sex organs for sexual reproduction.

\section{Other branches of Physiology}

Many branches use the word Physiology with them. The following are a few examples [21].

- Cell Physiology, Sports Physiology, Electrophysiology, High altitude Physiology,

\section{Space Physiology, Sleep Physiology, etc.}

\section{HUMAN PHYSIOLOGY: THE BASIS OF MEDICINE}

As mentioned earlier, Physiology is the study of normal functions of the body. Clinical Physiology includes the examinations and assessment of functions, along with structures (functional Anatomy). Well established clinical Physiology departments perform this assessment with the help of other specialties like clinical Neurophysiology, Nuclear Medicine, and Radiology. Departments, which lack this specialty in them, are constrained to perform these tests and assessments. Thus, developed health care systems can diagnose the problem in organisms with specificity [22].

Countries like Australia and the United Kingdom, 'Clinical physiologist,' is a term used to refer to an allied health professional or scientist, who may also work in different departments as an Ophthalmic Science Practitioner, cardiac scientist, respiratory scientist, vascular scientist, sleep scientist, etc. They are useful in the field of diagnosis of disease and managing the patients.

Knowledge of human Physiology may be used for the patients in hospitals is the important option of Clinical physiology [23]. Interventional procedures are done by Physiologists, like Echocardiography, MRI, Ultrasound, CT scan, nuclear scanner such as PET, SPECT are essential applications in diagnosis for a physic ian.

\section{Physiology: Linchin in the ARchWAy OF Medical AND SURGICAL ACQUAINTANCE}

Physiology, the study of normal functions, form the basis of Medicine and Surgery, which are concerned with the abnormal functions of the body. Medical Physiology uses its physiological model and explains the pathological conditions as a failure of body systems to function in their normal mode i.e. disturbance in homeostasis [24]. The immense contribution of Physiology to Medicine is that it explains the mechanism of disease and interprets the disease in terms of altered Physiology. Of late Physiology is considered as the "Institutes of Medicine" in the medical schools of England and Scotland. This factually means that physiology is the foundation of Medicine [25].

Laboratory findings are of great importance as they are useful in therapeutic innovation. An essential step is testing upon patients to check and prove that the application of physiological ideas and discovery is suitable to use the drugs as a remedy. Accordingly, the use of insulin for diabetes or the use of liver extract for pernicious anemia got discovered.

The application of the discovery to Medicine is often overwhelmed with difficulties equal to or even more significant than those of the 
original physiological discovery. Many a time, either physiological investigations or clinical application is overlooked. But it is not proper to do so because they both are like faces of the same coin. Thus, let us consider the matter more generally without keeping Physiology and Medicine in contention. It is clinical science that needs the stimulus to a new and more dynamic configuration. Clinical science must get more competitive research workers, who can lift scientific esteem of their branch and maintain its privileges, which can't be done by physicians, who are busy with their routine practice [26].

Finally, let me clarify and say that there is no thought of separating Physiology from Medicine in my mind. But I am trying to form a link between Medicine, Physiology, and Pathology through a group of researches who have the proper training and sufficient spare time to understand and apply the knowledge they possess with the best of their abilities. They have to be devoted to the tough job of recognizing and relieving the difficulties of ill persons.

An understanding of modern human Physiology assures an almost endless range of possibilities for careers in biomedicine, which can be practically combined with any other areas of biological sciences.

\section{PHYSIOLOGY BEYOND ACADEMICS IN THE ERA OF TRANSLATIONAL RESEARCH}

Physiology always appears to everyone as an academic subject and is only teaching based. This is a misconception that is still prevailing in the minds of all the medical and non-medical individuals. Numerous things make Physiology a unique subject, which forms the basis of all the knowledge forming the building blocks of medical science.

There are various fields where a physiologist can integrate themselves with clinicians. One among them is Sleep medicine and sleep disorders, which are ignored too much nowadays. But it is one of the most disturbing and problematic disorders. Sleep disorders such as Obstructive sleep apnoea needs much attention as it can have cardiovascular comorbidities associated with it. Basic sciences and Clinical departments should work hand in hand to handle the patients' burden.

Another field in Sports medicine/exercises Medicine and biomechanics. Biomechanics is a multidisciplinary science involving the application of mechanical principles in the study of the structure and function of the human body. Biomechanics describes the science involving the study of mechanical aspects of living organisms. It deals with the study of changes that takes place in the human body while doing exercise and thus to tone the body of athletes and sports personals in a way to achieve the maximum effect with minimum injuries and strain. It deals with the Aeronautics as well as the Space medicine too, where it takes into account the changes that can take place during travel in a gravity-free environment and the precautions to be taken [27].

Another field where a physiologist can interact with the clinicians, mainly the surgeons during their surgeries, is the Intraoperative neuromonitoring (IONM), where there will be continuous intraoperative monitoring of the neuronal activities during the brain and spinal cord surgeries. Continuous monitoring of the neuronal activity during surgery gives a warning about where to stop intervening with the nerve and when to continue the procedure. A physiologist well-versed with this neuromonitoring is a blessing for the orthopedic surgeon who carries out the vertebral surgeries. Other than this Physiology department can start the electrodiagnostic techniques lab in the hospitals, which in turn can help the clinicians a lot. They can carry out investigations like electroencephalogram, electromyogram, nerve conduction studies, polysomnography, autonomic function tests, which help in finding out and ruling out various disorders. Various research works can be of high scope in Physiology like carrying out animal studies, autonomic function tests like heart rate variability, and others in different study subjects.

\section{Conclusion}

Physiology is not an academic subject confined to teaching only, but it includes an exploration into the whole world of Medicine. But it needs interest, patience, and determination from the side of physiologists. So wake up and come out and explore the vast opportunities that Physiology provides.

\section{REFERENCES}

1. Kathryn $\mathrm{H}$ Myburgh. Origin and diversity of human physiological adaptability. Comparative Biochemistry and PhysiologyIn Molecular\& Integrative Physiology 2003;136(1):1-3

2. Nouwen A, Speight J, Pouwer F, Holt R.I.G. How psychological and behavioural research has shaped our understanding of diabetes. Diabetic Medicine 2020;37(3): 377-9

3. Coxon RV. The Physiological Basis of Medical Practice. Quarterly Journal of Experimental Physiology and Cognate Medical Sciences $1961 ; 46(4): 400-2$

4. Willmer P. How Molecules Make Organisms Work. Science 2002; 296 (5567): 473

5. Ueda H. Organism-level systems biology by next-generation genetics and whole-organ cell profiling. IBRO Reports 2019; 6: 38-39.

6. Mcpherran ML. Socrates, Crito, and their Debt to Asclepius. Ancient Philosophy 2003;23(1): 71-92 
7. Fernel JJ, Forrester, Henry J. The "Physiologia" of Jean Fernel (1567). In: Transactions of the American Philosophical Society 2003;93(1).

8. Karbhari.Y. Cross-border control. Emergency Nurse 2015; 23(6): 39-39.

9. Hawes.J. Early Pulmonary Tuberculosis: Diagnosis, Prognosis, and Treatment. Southern Medical Journal 1914; 7(1): 85.

10. Gakis D. The Hippocratic Oath today. MOJ Surgery 2016; 3(2): 35

11. Rahmatullah. M. Tribal Medicinal Plants: Documentation of Medicinal Plants Used by a Mogh Tribal Healer in Bandarban District, Bangladesh. Archives of Pharmacy \& Pharmacology Research 2019;1(5):12

12. Giuffrida-Ruggeri. V. Were the Pre-Dynastic Egyptians Libyans or Ethiopians. Man 1951;15: 51

13. Shalaby SF, Soliman MA. Knowledge, attitude, and practice of medical students regarding smoking and substance abuse, Cairo University, Egypt. Journal of the Egyptian Public Health Association 2019;94(11): 1-9

14. Schlerath. B. The Atharvaveda. Sanskrit text with English translation with glossary and index. Ed. by D. CHAND. Kratylos 2002;47(1): 156-7

15. Patwardhan. B. Traditional knowledge patents: New guidelines or deterrents. Journal of Ayurveda and Integrative Medicine 2013; 4(1): 1

16. Das S. Susruta Samhita - A Medico-Surgical Teaching Compendium by Susruta of Ancient India. Journal of Urology 2014;191(4): 1-4

17. Tong XQ, Xie G, Rong S, ZhouQ. Meng. Detection of consensuses and treatment principles of diabetic nephropathy in traditional Chinese Medicine: A new approach. Journal of Traditional Chinese
Medical Sciences 2015; 2(4): 270-83.

18. Harvey W. In: An Anatomical Disquisition on the Motion of the Heart and Blood in Animals. Annals of Non-invasive Electro cardiology 2000; 5(2): 196-203

19. Vasil I. A history of plant biotechnology: from the Cell Theory of Schleiden and Schwann to biotech crops. Plant Cell Reports 2008; 27(9):1423-40

20. Tim Newman. Introduction to Physiology: History, biological systems, and branches. Medical news today 2017:1-2

21. Anderson RE. Billions for Defense: the pervasive nature of defensive Medicine. Archives of Internal Medicine 1999;159(20): 2399-402

22. Eissing TA Computational Systems Biology Software Platform for Multiscale Modeling and Simulation: Integrating Whole-Body Physiology, Disease Biology, and Molecular reaction Networks. Frontiers in Physiology $2011 ; 2: 1-2$

23. Colbert D. Fundamentals of clinical physiology. Comparative Biochemistry and Physiology part A: Physiology 1993;106(2): 403

24. Shi Z. Clinical Exercise Physiology and Health Care. Research \& Investigations in Sports Medicine 2018;1(5): 94-5

25. Howe A, Campion P, Searle J, Smith $H$. New perspectives-approaches to medical education at four new UK medical schools. BMJ 2004; 329: 327-331.

26. Auger P. The Semaines' Dissemination in England and Scotland until 1641. Renaissance studies 2012; 26(5): 625-40

27. Kanchan Yadav. Physiology beyond academics in the era of translation research. In JIPMER conference on Physiology. Puducherry. 2017:11-4. 